\title{
(- OPEN ACCESS \\ Cutaneous lymphangitis carcinomatosa made cervicofacial oedema intractable in a patient with superior vena cava syndrome
}

\author{
Eriko Kashihara, ${ }^{1}$ Osamu Kanai, ${ }^{2}$ Misato Okamura, ${ }^{2}$ Tadashi $\mathrm{Mio}^{2}$
}

'Division of General Medicine, National Hospital Organization Kyoto Medical Center, Kyoto, Japan

${ }^{2}$ Division of Respiratory Medicine, National Hospital Organization Kyoto Medical Center, Kyoto, Japan

Correspondence to Dr Osamu Kanai, geminus75@gmail.com

Accepted 30 March 2018
Check for updates

To cite: Kashihara $\mathrm{E}_{\text {, }}$ Kanai O, Okamura M, et al. BMJ Case Rep Published Online First: [please include Day Month Year]. doi:10.1136/bcr-2018224206

\section{SUMMARY}

Cutaneous lymphangitis carcinomatosa (CLC) is a rare form of cutaneous metastasis that causes lymphoedema and various eruptions. We report a case of lung cancer with CLC that caused both superior vena cava (SVC) stenosis and cervicofacial oedema, suggestive of SVC syndrome. A 64-year-old woman with lung adenocarcinoma presented with cervicofacial oedema and erythema, followed by severe dyspnoea 2 months after four cycles of carboplatin, pemetrexed and bevacizumab triplet therapy. Although chest CT indicated SVC stenosis, cervicofacial oedema remained despite treating the SVC stenosis via balloon dilation. A skin biopsy of the erythematic sample confirmed CLC as the cause of the patient's symptoms. CLC should be considered as a differential diagnosis of cervicofacial oedema in addition to SVC syndrome, especially when it is observed in combination with skin erythema and induration. Moreover, a skin biopsy should be performed promptly for accurate diagnosis of CLC and to decide on appropriate treatment.

\section{BACKGROUND}

When lung cancer progression causes symptoms that reduce the ability to manage daily activities, adequate symptom treatment is required. Superior vena cava (SVC) syndrome is a major complication of lung cancer that occurs when the lung tumour compresses the SVC extrinsically, which causes cervicofacial oedema and dyspnoea. ${ }^{1}$ Among treatment options for SVC syndrome, an indwelling SVC stent effectively improves symptoms within a few days. ${ }^{1}$ Cutaneous lymphangitis carcinomatosa (CLC), a rare condition that accounts for less than $5 \%$ of cutaneous metastases, also causes cervicofacial oedema, ${ }^{2}$ and patients with CLC usually present with progressive lymphoedema and erythema. ${ }^{3}$ Here, we report a rare case of lung adenocarcinoma with CLC and SVC stenosis in a patient whose cervicofacial oedema and dyspnoea remained despite improving SVC blood flow via balloon dilation.

\section{CASE PRESENTATION}

A 64-year-old woman with a 20-pack-year smoking history presented with a persistent cough for 3 months. Chest CT showed a $10 \mathrm{~mm}$-diameter nodule in the right upper lobe of her lung and swelling of the supraclavicular, mediastinal and right hilar lymph nodes. Tissue samples obtained via mediastinoscopy indicated adenocarcinoma harbouring EGFR mutations: G719S (exon 18) and T790M (exon 20). Enhanced brain MRI showed frontal and occipital brain metastases. Thus, the patient was diagnosed with stage IV lung adenocarcinoma (cT1aN3M1b) based on the seventh edition of the Union for International Cancer Control Tumour-Node-Metastasis classification of Malignant Tumours. She achieved partial response after four cycles of carboplatin, pemetrexed and bevacizumab triplet therapy, which was discontinued due to drug-induced interstitial pneumonia.

Two weeks after the onset of drug-induced interstitial pneumonia, the patient developed prominent oedema and erythema in her neck and face, followed by dyspnoea (figure 1A,B). Contrast-enhanced CT revealed severe SVC stenosis, which suggested that the symptoms primarily resulted from SVC syndrome (figure 2). The patient underwent angiography and balloon dilation, after which SVC blood flow remained, despite prominent stenosis. Although the SVC was dilated by the procedure, cervicofacial oedema and dyspnoea improvement was observed for only a few hours. Chest CT performed the following day revealed that the SVC remained constricted, suggesting the existence of other causes that made the patient's symptoms more intractable (figure 3 ).

Concomitantly, the patient developed painless erythema and induration of the chest and abdomen. Before angiography, a skin biopsy was performed at the erythematic site, which revealed neoplastic cells within the lumina of dermal lymphatic vessels and infiltration into the dermis and hypodermis (figure 4A). Immunohistochemistry staining revealed that the cells were positive for cytokeratin, thyroid transcription factor- 1 and napsin $\mathrm{A}$ (figure 4B,C). From these results, we diagnosed the cause of oedema and dyspnoea of the patient as CLC and SVC syndrome.

\section{OUTCOME AND FOLLOW-UP}

The patient died of respiratory failure 1 week after CLC diagnosis.

\section{DISCUSSION}

We reported a case of lung adenocarcinoma with a combination of CLC and SVC stenosis, which presented with cervicofacial oedema and dyspnoea. Balloon dilation failed to improve these symptoms, 


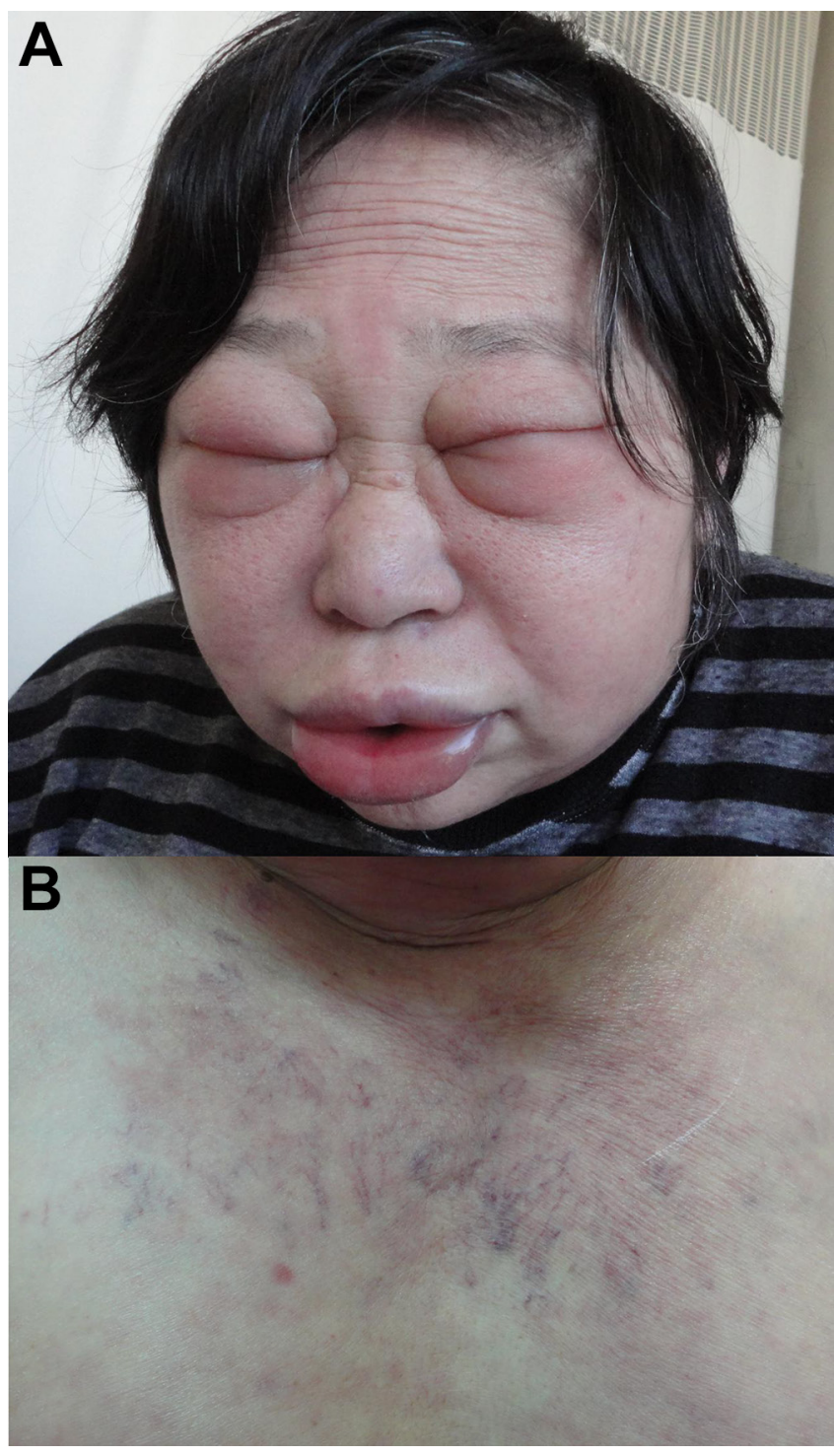

Figure 1 Photographs of the patient presenting with prominent oedema in the face and neck and with painless erythema and induration of the chest.

which suggests that CLC made the symptoms caused by SVC syndrome more intractable.

In the present case, when the patient presented with swelling and erythema of the neck and chest collateral veins and dyspnoea, CT revealed SVC stenosis. This disease course is typical of SVC syndrome, which was the main cause of the symptoms. SVC syndrome arises from the compression of thin-walled SVC by enlarged paratracheal lymph nodes, mostly caused by lung cancer. ${ }^{1}$ The common symptoms of SVC syndrome include neck swelling, dyspnoea, facial swelling, cough and dilated chest collateral veins. ${ }^{1}$ Contrast-enhanced CT may elucidate the cause and extent of venous obstruction in SVC syndrome. The initial treatment in emergent cases of SVC syndrome is endovascular stenting of the SVC to restore flow. SVC stenting is reported to improve symptoms of SVC syndrome within 1-3 days, and recurrence rarely occurs. ${ }^{1}$ In the present case, SVC blood flow remained despite its prominent stenosis, and symptoms improved for only a few hours. The rapid recurrence of symptoms is atypical for SVC syndrome and indicates that there were other causes that made the patient's symptoms more intractable.

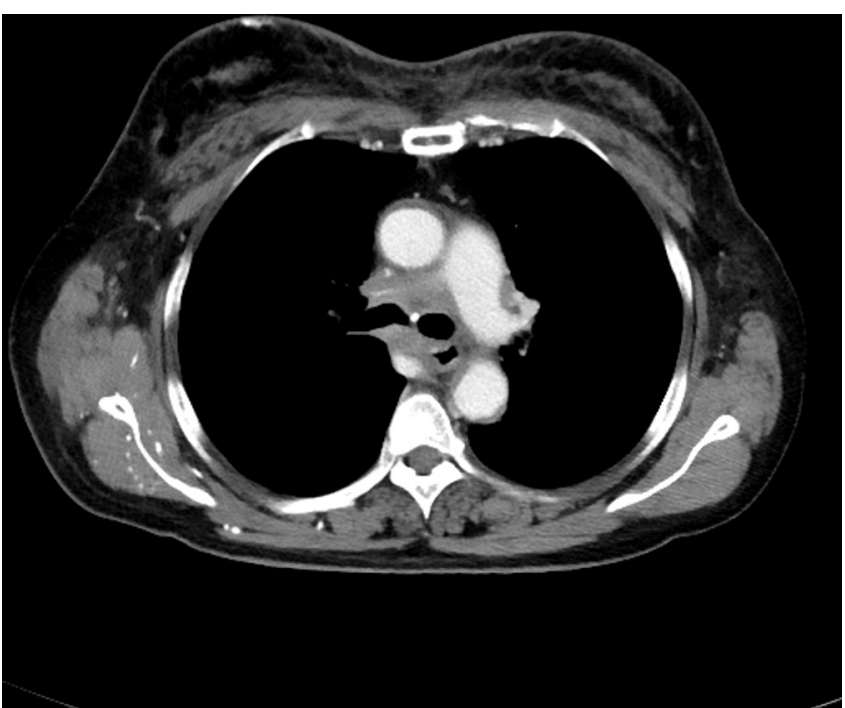

Figure 2 An axial image of contrast-enhanced CT acquired when the patient developed cervicofacial oedema. The image reveals stenosis of the superior vena cava.

In the present case, the patient presented with induration of the chest and abdomen, and a prompt skin biopsy confirmed the diagnosis of CLC. CLC is a rare form of skin metastases that exhibits extensive dermal and subcutaneous lymphatic invasion. This subcutaneous lymphatic invasion results in lymphoedema and diffuse skin erythema mimicking an infectious process, which differs from the typical form of cutaneous metastases such as nodules or masses. ${ }^{3-6}$ The incidences of cutaneous metastases in patients with metastatic cancer and with lung cancer are approximately $5 \%$ and $1.7 \%-3.1 \%$, respectively; CLC accounts for approximately $5 \%$ of all cutaneous metastases. ${ }^{2} 7$ The most common histological feature observed in patients with lung cancer who develop CLC is adenocarcinoma, as in the present case. ${ }^{8}$ Cutaneous metastasis in lung cancer tends to occur in order in the anterior chest wall, back and abdomen. ${ }^{7-11}$ Cutaneous metastases are considered a late event in the evolution

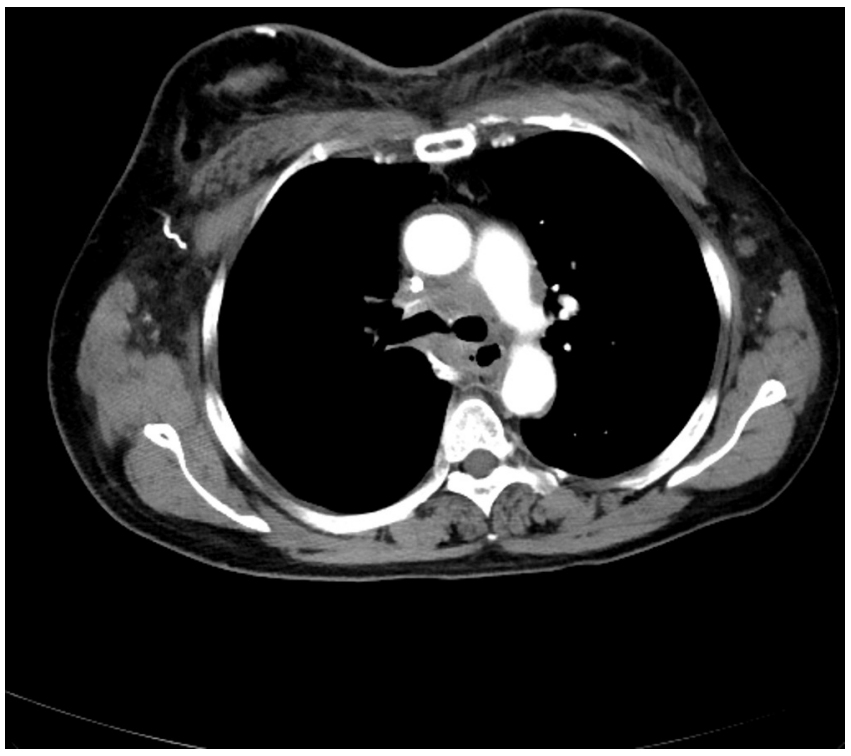

Figure 3 An axial image of contrast-enhanced CT acquired on the day following balloon dilation. The image shows that the superior vena cava remained constricted. 


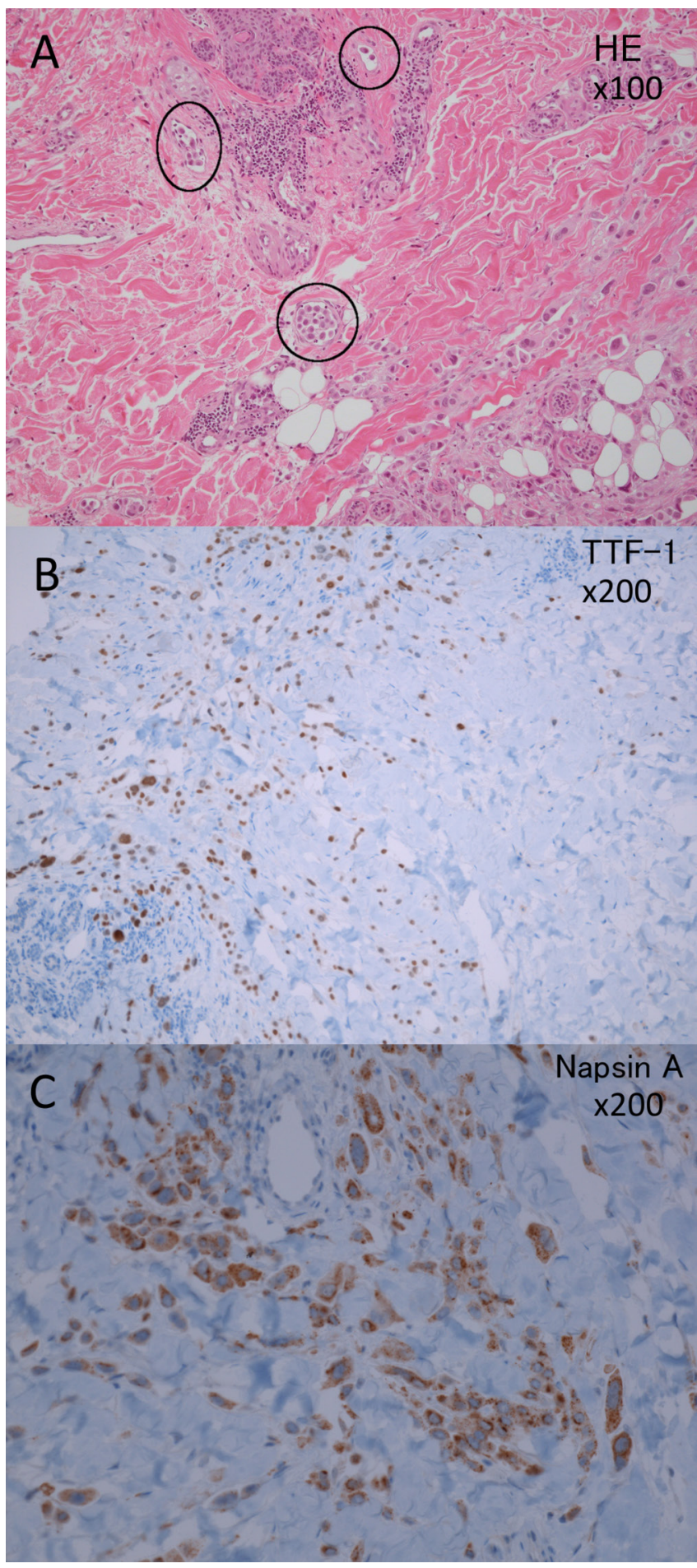

Figure 4 Histological images of tissue samples obtained from the skin biopsy. Black circles indicate that neoplastic cells exist in the lumen of dermal lymphatic vessels and infiltrate the dermis and hypodermis (hematoxylin and eosin staining, $\times 100)(A)$ Immunohistochemical staining at 200-fold magnification shows positivity for thyroid transcription factor-1 (B) and napsin A (C).

of the majority of malignancies. ${ }^{9}$ Lung cancer is the quickest to metastasise to the skin (15.75 months) among solid tumours. ${ }^{3}$ The average survival time from the appearance of CLC in lung cancer (less than 3 months) is shorter than that from the appearance of cutaneous metastasis (3 to 5 months). ${ }^{3712}$ The only known treatment for CLC is systemic chemotherapy, but early diagnosis can lead to earlier anticancer treatment. ${ }^{8}$ Osimertinib may improve the prognosis of the patients harbouring the EGFR T790M mutation; however, osimertinib was not available for treatment at the time of this diagnosis. ${ }^{13-15}$ Supportive care for lymphoedema due to CLC, as follows, can improve patients' quality of life and may even influence the progression of the disease: manual lymph drainage, compression therapy with bandages or special stockings, dermatological skin care and psychological treatment. $^{3}$

In conclusion, CLC and SVC syndrome can both cause cervicofacial oedema and dyspnoea, and concurrence of CLC and SVC makes the symptoms more intractable. When a patient with lung cancer and cervicofacial oedema develops erythema and induration atypical of SVC syndrome, we recommend a prompt skin biopsy for accurate diagnosis and for deciding on appropriate therapy.

\section{Learning points}

- Superior vena cava (SVC) syndrome is the major cause of cervicofacial oedema occurring in patients with malignancies, especially lung cancer.

- Cutaneous lymphangitis carcinomatosa (CLC), a rare form of cutaneous metastasis that causes lymphoedema and various erythemas, may also cause cervicofacial oedema similar to that observed in SVC syndrome.

- If the patients who developed cervicofacial oedema and SVC stenosis are refractory to the treatment of SVC syndrome, including endovascular stenting or radiotherapy, concurrence of CLC should be considered.

Contributors EK wrote and revised the draft, and made the conception of this work. OK revised the draft and advised for the content of discussion part. MO was involved in the treatment of the patient and got a consent form. TM advised for the content of case presentation, especially for the images which should be used for publication.

Funding The authors have not declared a specific grant for this research from any funding agency in the public, commercial or not-for-profit sectors.

Patient consent Next of kin consent obtained.

Provenance and peer review Not commissioned; externally peer reviewed.

Open Access This is an Open Access article distributed in accordance with the Creative Commons Attribution Non Commercial (CC BY-NC 4.0) license, which permits others to distribute, remix, adapt, build upon this work non-commercially, and license their derivative works on different terms, provided the original work is properly cited and the use is non-commercial. See: http://creativecommons.org/ licenses/by-nc/4.0/

(c) BMJ Publishing Group Ltd (unless otherwise stated in the text of the article) 2018. All rights reserved. No commercial use is permitted unless otherwise expressly granted.

\section{REFERENCES}

1 Straka C, Ying J, Kong FM, et al. Review of evolving etiologies, implications and treatment strategies for the superior vena cava syndrome. Springerplus 2016;5

2 Marcoval J, Moreno A, Peyrí J. Cutaneous infiltration by cancer. J Am Acad Dermatol 2007:57:577-80

3 Damstra RJ, Jagtman EA, Steijlen PM. Cancer-related secondary lymphoedema due to cutaneous lymphangitis carcinomatosa: clinical presentations and review of literature. Eur J Cancer Care 2010;19:669-75.

4 Arfi A, Clavier A, Honart JF, et al. Blue Lymphangitis of the Breast after Breast Cancer: Case Report. Breast J 2017;23:348-51.

5 Saeed S, Keehn CA, Morgan MB. Cutaneous metastasis: a clinical, pathological, and immunohistochemical appraisal. J Cutan Pathol 2004;31:419-30.

6 Palaia I, Angioli R, Cutillo G, et al. Skin relapse from cervical cancer. Gynecol Oncol 2002;87:155-6.

7 Hidaka T, Ishii Y, Kitamura S. Clinical features of skin metastasis from lung cancer Intern Med 1996;35:459-62. 


\section{Reminder of important clinical lesson}

8 Prat L, Chouaid C, Kettaneh A, et al. Cutaneous lymphangitis carcinomatosa in a patient with lung adenocarcinoma: case report and literature review. Lung Cancer 2013;79:91-3.

9 Lookingbill DP, Spangler N, Helm KF. Cutaneous metastases in patients with metastatic carcinoma: a retrospective study of 4020 patients. J Am Acad Dermatol 1993;29:228-36.

10 Kobayashi K, Nakachi I, Naoki K, et al. Real-world Efficacy and Safety of Nivolumab for Advanced Non-Small-cell Lung Cancer: A Retrospective Multicenter Analysis. Clin Lung Cancer 2018.

11 Dhambri S, Zendah I, Ayadi-Kaddour A, et al. Cutaneous metastasis of lung carcinoma: a retrospective study of 12 cases. J Eur Acad Dermatol Venereol 2011;25:722-6.
12 Marcoval J, Penín RM, Llatjós R, et al. Cutaneous metastasis from lung cancer: retrospective analysis of 30 patients. Australas J Dermatol 2012;53:288-90.

13 Goss G, Tsai CM, Shepherd FA, et al. Osimertinib for pretreated EGFR Thr790Metpositive advanced non-small-cell lung cancer (AURA2): a multicentre, open-label, single-arm, phase 2 study. Lancet Oncol 2016;17:1643-52.

14 Yang JC, Ahn MJ, Kim DW, et al. Osimertinib in pretreated T790M-Positive advanced non-small-cell lung cancer: AURA Study Phase II extension component. J Clin Oncol 2017;35:1288-96.

15 Soria JC, Ohe Y, Vansteenkiste J, et al. Osimertinib in untreated EGFR-mutated advanced non-small-cell lung cancer. N Eng/ J Med 2018;378:113-25.

Copyright 2018 BMJ Publishing Group. All rights reserved. For permission to reuse any of this content visit

http://group.bmj.com/group/rights-licensing/permissions.

BMJ Case Report Fellows may re-use this article for personal use and teaching without any further permission.

Become a Fellow of BMJ Case Reports today and you can:

- Submit as many cases as you like

- Enjoy fast sympathetic peer review and rapid publication of accepted articles

- Access all the published articles

Re-use any of the published material for personal use and teaching without further permission

For information on Institutional Fellowships contact consortiasales@bmjgroup.com

Visit casereports.bmj.com for more articles like this and to become a Fellow 